Article

\title{
NF-кB-Targeted Anti-Inflammatory Activity of Prunella vulgaris var. lilacina in Macrophages RAW 264.7
}

\author{
Yu-Jin Hwang ${ }^{1,2}$, Eun-Ju Lee ${ }^{1}$, Haeng-Ran Kim ${ }^{1}$ and Kyung-A Hwang ${ }^{1}{ }_{*}$
}

1 Department of Agrofood Resources, National Academy of Agricultural Science, RDA, Suwon, Gyeonggi-do 441-853, Korea; E-Mails: yujinh21@skku.edu (Y.-J.H.); bono2180@naver.com (E.-J.L.); kimhrr@korea.kr (H.-R.K.)

2 Department of Biotechnology \& Bioengineering, Sungkyunkwan University, Suwon, Gyeonggi-do 440-746, Korea

* Author to whom correspondence should be addressed; E-Mail: kah366@korea.kr; Tel.: +82-31-299-0527; Fax: +82-31-299-0504.

Received: 24 August 2013; in revised form: 29 September 2013 / Accepted: 23 October 2013 / Published: 30 October 2013

\begin{abstract}
Prunella vulgaris var. lilacina, a herbal medicine, has long been used in Korea for the treatment of sore throat, and to alleviate fever and accelerate wound healing. Although the therapeutic effect of $P$. vulgaris var. lilacina is likely associated with anti-inflammatory activity, the precise underlying mechanisms are largely unknown. Here, we sought to elucidate the possible mechanisms of the anti-inflammatory activity. We have investigated the anti-inflammatory activity of the various solvent fractions (hexane, butanol, chloroform and water) from the ethanol extract of P. vulgaris var. lilacina in activated macrophages. The hexane fraction exhibited higher anti-inflammatory activities, inducing inhibition of nitric oxide and prostaglandin E2 production as well as inducible nitric oxide synthase, cyclooxygenase-2, and tumor necrosis factor- $\alpha$ mRNA expression in response to lipopolysaccharide stimulation. Moreover, the hexane fraction from $P$. vulgaris var. lilacina significantly inhibited the activation of the nuclear factor kappa-light-chain-enhancer of activated $\mathrm{B}$ cells $(\mathrm{NF}-\kappa \mathrm{B})$ and the nuclear translocation of the NF-кB p50 and p65 subunits. These results indicate that $P$. vulgaris var. lilacina has an anti-inflammatory capacity in vitro, suggesting that it could be a potential source of natural anti-inflammatory agents.
\end{abstract}

Keywords: Prunella vulgaris var. lilacina; anti-inflammation; NO; PGE2; NF-кB 


\section{Introduction}

Inflammation is the primary response to infection or injury and is critical for both innate and adaptive immunity $[1,2]$. Inflammation can be measured by the use of various markers such as nuclear factor kappa-light-chain-enhancer of activated B cells (NF- $\kappa \mathrm{B})$, tumor necrosis factor- $\alpha$ (TNF $\alpha$ ), cyclooxygenase (COX), and nitric oxide (NO). In particular, NF- $\mathrm{B}$ is an important transcription factor that induces the transcription of proinflammatory mediators, such as inducible nitric oxide synthase (iNOS) and COX-2, which are involved in the activation of inflammatory and immune responses [3-5]. Since activation of NF- $\mathrm{KB}$ leads to inflammation that in turn is involved in the pathogenesis of many diseases such as asthma, rheumatoid arthritis, and inflammatory bowel disease [6], much attention has focused on the development of anti-inflammatory drugs targeting NF- $\mathrm{B}$ [7].

Due to the resistance of such diseases to conventional treatment, as well as the side effects of presently available anti-inflammatory drugs, there is a pressing need for the development of novel anti-inflammatory drugs. In this regard, recent efforts are focusing on finding natural products that show anti-inflammatory properties [8]. Several compounds have shown anti-inflammatory activity; among them, phenolic compounds have attracted great attention due to both their large distribution among dietary components and the variety of biological activities that they display [9].

Prunella vulgaris var. lilacina is a perennial herb that is widely distributed in Korea, China, Japan, and Europe. P. vulgaris var. lilacina has been used as a traditional medicine to alleviate sore throat, reduce fever, and accelerate wound healing. In addition, this herb has been shown to have anti-inflammatory, anti-oxidant, anti-allergic, anti-microbial, anti-viral, and free radical scavenging activities [10,11]. P. vulgaris var. lilacina contains various compounds which are flavonoids, triterpenoids, phenolic acids such as campherol, rutin, rosmarinic acid, caffeic acid, and tannins that provide a great assortment of biological properties [12].

Several studies related to $P$. vulgaris var. lilacina have provided evidence that the ethanol extracts of this herb can suppress inflammation by inhibiting nitrite and prostaglandin E2 (PGE2) production by macrophages, suppressing the NF- $\mathrm{B}$ activity [13-16]. Nevertheless, the studies have not yet considered the anti-inflammatory effects of the various solvent fractions of P. vulgaris var. lilacina. Thus, in this study, we focused on evaluating the effects of the various solvent fractions from the ethanol extracts of $P$. vulgaris var. lilacina in preventing inflammation. We also investigated a potential mechanism for the anti-inflammatory effect of $P$. vulgaris var. lilacina in association with $\mathrm{NF}-\kappa \mathrm{B}$ inhibition.

\section{Results and Discussion}

\subsection{Effect of $\mathrm{P}$. vulgaris var. lilacina on Viability of $R A W 264.7$ Cells}

The inhibitory effect of $P$. vulgaris var. lilacina on RAW 264.7 cell viability was determined by intracellular ATP content (Figure 1). Cells were treated with fractions of P. vulgaris var. lilacina at various concentrations $(0,10,50$, and $100 \mu \mathrm{g} / \mathrm{mL})$ for $1 \mathrm{~h}$ and then co-incubated with lipopolysaccharides (LPS; $1 \mu \mathrm{g} / \mathrm{mL}$ ) for an additional $24 \mathrm{~h}$. 
Figure 1. Effects of solvent fractions from Prunella vulgaris var. lilacina on the viability of RAW 264.7 cells. (A) Lipopolysaccharide (LPS) untreated; (B) LPS treated. Bars represent the mean and standard deviations from three different experiments performed in triplicate. ${ }^{*} p<0.05$ significantly different from the LPS group.

(A)

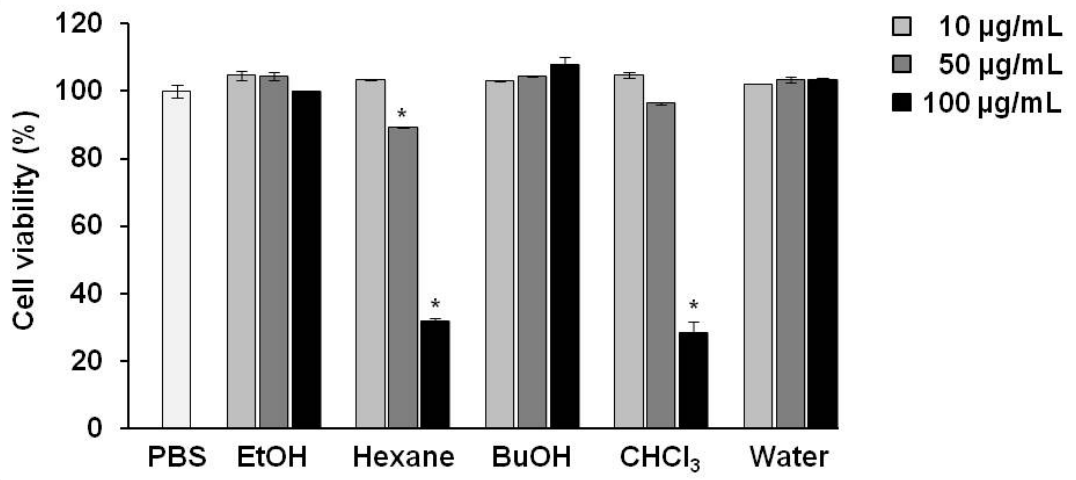

(B)

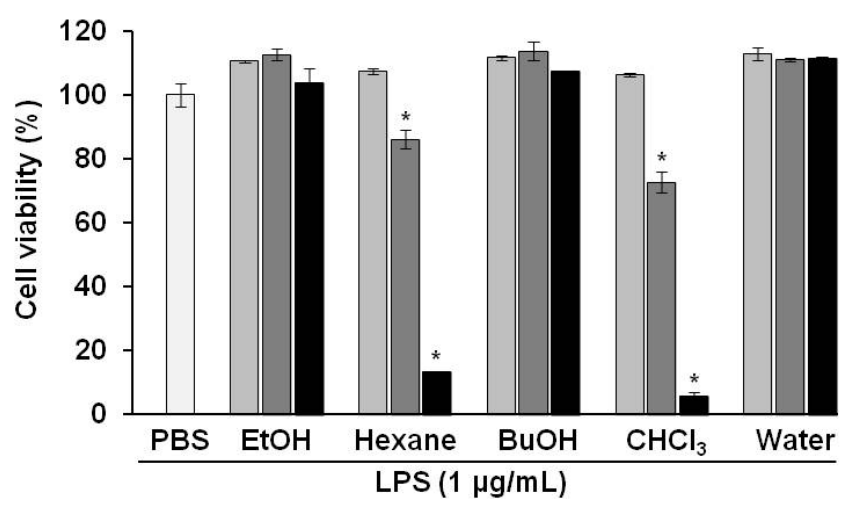

We estimated the influence on cell survival according to the following criteria: Cell viability values greater than $90 \%$ were considered unaffected by tested compounds, $80 \%-90 \%$ was modestly affected, and values less than $80 \%$ were considered affected by the cytotoxic effects of the compounds.

Our results showed that the various fractions of $P$. vulgaris var. lilacina had no cytotoxic effects on RAW 264.7 cells at concentrations of $10 \mu \mathrm{g} / \mathrm{mL}$. For the hexane fractions $(50 \mu \mathrm{g} / \mathrm{mL})$, the viability of RAW 264.7 cells after exposure was $85 \%$, which, according to our criteria, was a modest effect and was not considered cytotoxic in other reported studies [17-19]. In contrast, the group treated with chloroform $\left(\mathrm{CHCl}_{3}\right)$ fractions resulted in a cell viability value of $73 \%$. Therefore, except for the chloroform fractions, all fractions of $P$. vulgaris var. lilacina from 10 to $50 \mu \mathrm{g} / \mathrm{mL}$ were selected for subsequent experiments.

\subsection{Effect of $\mathrm{P}$. vulgaris var. lilacina on LPS-Induced NO and PGE2 Production}

We next investigated whether $P$. vulgaris var. lilacina might have anti-inflammatory properties in LPS-stimulated RAW 264.7 cells. Various concentrations $(0,10$, and $50 \mu \mathrm{g} / \mathrm{mL})$ of $P$. vulgaris var. lilacina fractions were used on RAW 264.7 cells to test whether P. vulgaris var. lilacina could reverse LPS-induced accumulation of NO and PGE2. The results revealed that LPS $(1 \mu \mathrm{g} / \mathrm{mL})$ treatment for $24 \mathrm{~h}$ markedly increased NO and PGE2 production as compared with control group; however, P. vulgaris var. lilacina fractions significantly inhibited the production of these factors in a dose-dependent 
manner (Figure 2). In particular, NO and PGE2 secretion decreased by $40 \%$ and $60 \%$, respectively, in cells exposed to the hexane fraction of P. vulgaris var. lilacina. For the chloroform fraction, NO secretion was strongly inhibited, suggesting that the chloroform fraction may influence cell death. Huang et al. [16] demonstrated that the ethanol extract of $P$. vulgaris inhibited LPS-induced PGE2 and NO production by $10 \%-35 \%$. Our results are consistent with their reports. The remarkable aspect of our study is that we observed a stronger inhibition than their results. These results could be affected by various extracted compounds come from difference of composition of the solvent which were likely due to our using $70 \%$ ethanol for extraction instead of $95 \%$ ethanol as was used by the other group.

Figure 2. Effects of the solvent fractions from Prunella vulgaris var. lilacina on LPS-induced nitric oxide (NO) (A) and prostaglandin E2 (PGE2); (B) production in RAW 264.7 cells. Values show the means and standard deviations of three different experiments performed in triplicate. ${ }^{*} p<0.05$ significantly different from the LPS-treated PBS group.

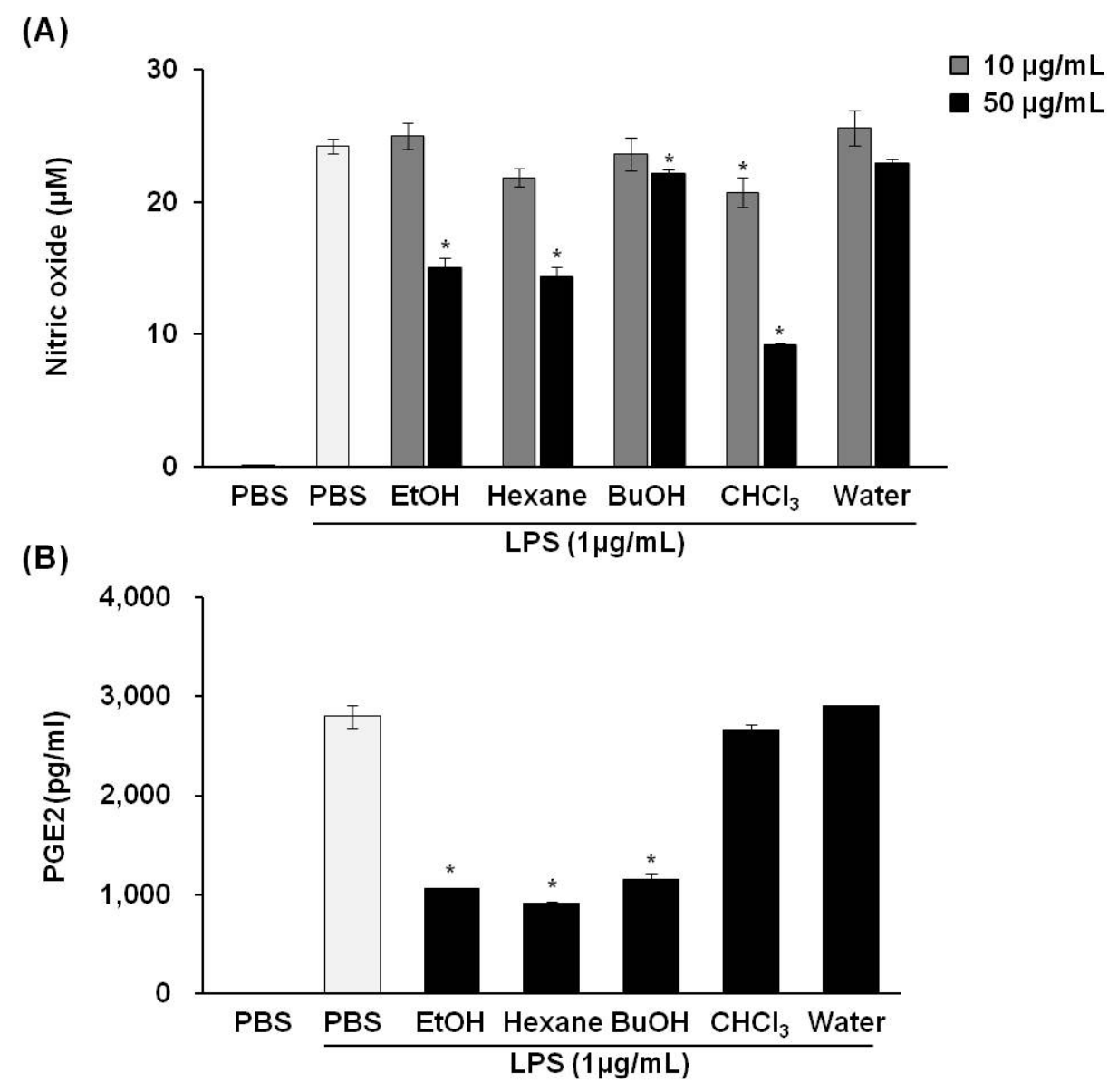

\subsection{Effect of $\mathrm{P}$. vulgaris var. lilacina on LPS-Induced iNOS and COX-2 Expression}

NO is acknowledged as a mediator and regulator of the inflammatory response and is made in large amounts by iNOS in activated inflammatory cells [20]. The enzymatic activity of COX-2 also can be influenced directly by NO and iNOS [21]. To elucidate the mechanisms of inhibition for the hexane fraction against NO and PGE2 production in LPS-stimulated RAW 264.7 cells, we assessed whether the inhibitory effects of $P$. vulgaris var. lilacina on these inflammatory mediators were related to iNOS and COX-2 protein and mRNA levels using western blot and real-time reverse transcription 
polymerase chain reaction (RT-PCR) analyses, respectively. The level of iNOS and COX-2 mRNA and protein expression was significantly elevated in macrophages treated with LPS. Treatment with P. vulgaris var. lilacina fractions attenuated LPS-induced iNOS and COX-2 expression (Figure 3). These results suggest that the inhibitory effect of the fractions on LPS-induced NO and PGE2 production was mediated by the inhibition of iNOS and COX-2 expression.

Figure 3. Effects of solvent fractions from Prunella vulgaris var. lilacina on LPS-induced pro-inflammatory mRNA expression and protein levels in RAW 264.7 cells. Cells were treated with fractions $(50 \mu \mathrm{g} / \mathrm{mL})$ and stimulated with LPS $(1 \mu \mathrm{g} / \mathrm{mL})$ for $12 \mathrm{~h}$. (A,B) After incubation, cells were harvested for real-time RT-PCR to determine mRNA expression for (A) iNOS and (B) COX-2. (C) After incubation, cell lysates were used to determine iNOS and COX-2 protein levels via Western blot. Values show the means and standard deviations of three different experiments performed in triplicate. ${ }^{*} p<0.05$ significantly different from the LPS-treated PBS group.

(A)

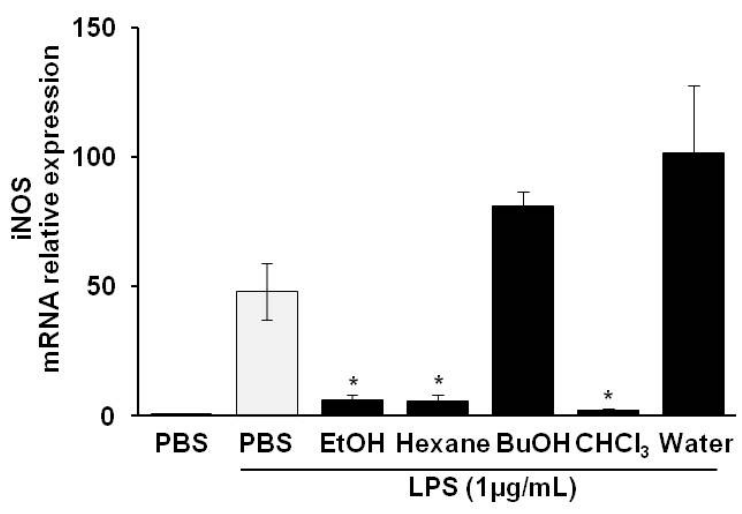

(C)

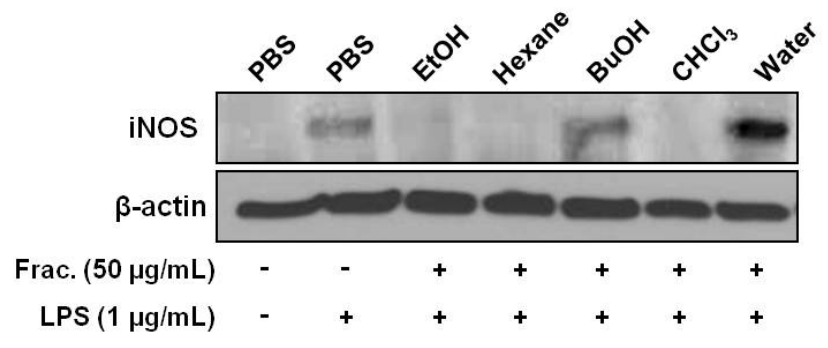

(B)
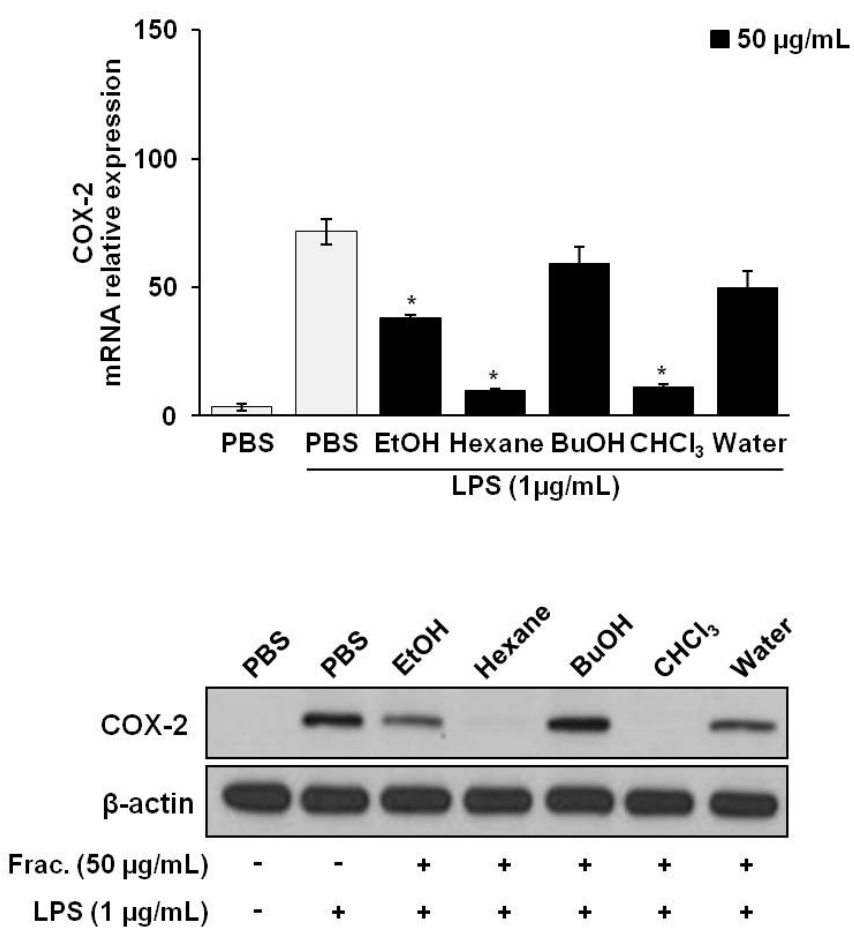

\subsection{Effect of $\mathrm{P}$. vulgaris var. lilacina Fractions on TNFa Production}

When macrophages are treated with LPS, the pro-inflammatory cytokine TNF- $\alpha$ is also increased and has an important role in the activation of NO and PGE2 [22]. Therefore, we examined the effect of treatment with $P$. vulgaris var. lilacina fractions on the mRNA expression and secretion of TNF $\alpha$ in LPS-stimulated RAW 264.7 cells. TNF $\alpha$ production was assessed in the culture supernatant by an ELISA. We found that TNF $\alpha$ was expressed at low levels in untreated controls (Figure 4). However, LPS stimulation significantly increased TNF $\alpha$ secretion at $24 \mathrm{~h}$. The treatment with $P$. vulgaris var. lilacina fractions significantly suppressed LPS-induced TNFa secretion (Figure 4A). To evaluate whether the reduction in LPS-induced TNFa levels by P. vulgaris var. lilacina was due to the regulation of the 
TNF $\alpha$ gene in RAW 264.7 cells, we performed RT-PCR analysis. Similar to the results for TNF $\alpha$ secretion, P. vulgaris var. lilacina reduced the LPS-induced expression of TNF $\alpha$ mRNA (Figure 4B). These data indicate that $P$. vulgaris var. lilacina suppresses TNF $\alpha$ release at the transcriptional level.

Figure 4. Effects of solvent fractions from Prunella vulgaris var. lilacina on LPS-induced TNF $\alpha$ levels (A) and TNF $\alpha$ mRNA expression (B) in RAW 264.7 cells. Cells were treated with fractions $(50 \mu \mathrm{g} / \mathrm{mL})$ and stimulated with LPS $(1 \mu \mathrm{g} / \mathrm{mL})$ for $12 \mathrm{~h}$. Values show the means and standard deviations of three different experiments performed in triplicate. $* p<0.05$ significantly different from the LPS-treated PBS group.

(A)

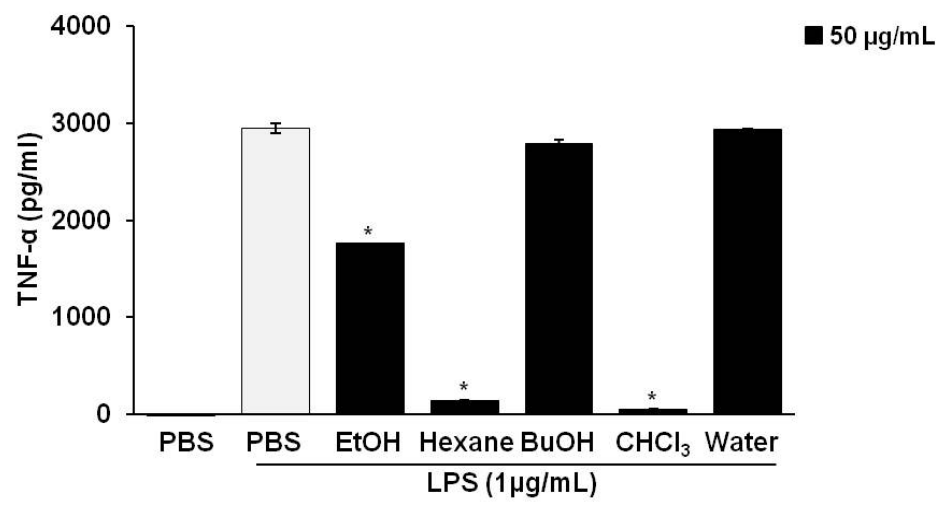

(B)

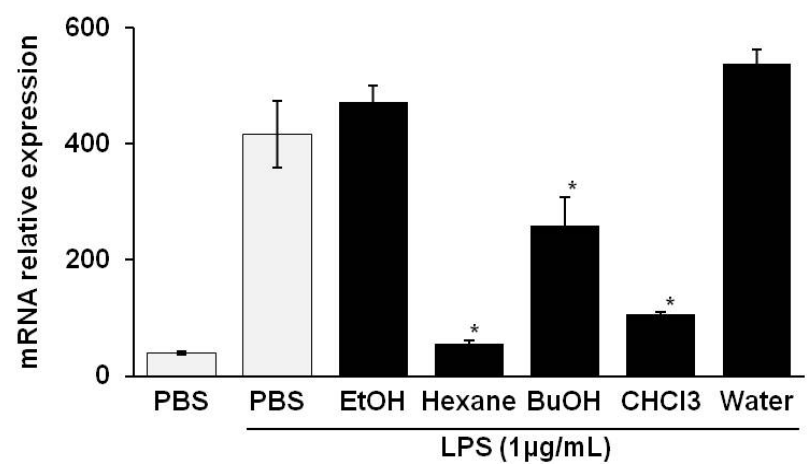

\subsection{Effects of $\mathrm{P}$. vulgaris var. lilacina on $N F-\kappa B$ Activity and Translocation of $N F-\kappa B$ Subunits}

The expression of iNOS and COX-2 requires the activation of NF- $\mathrm{B}$, which is an important mechanism for the overproduction of the inflammatory mediators in macrophages in response to LPS

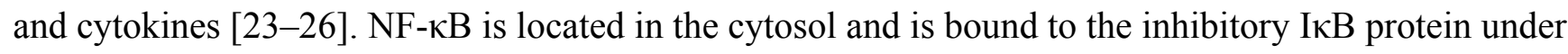
unstimulated conditions. The activation of NF- $\mathrm{BB}$ in response to LPS stimulation leads to an increase in nuclear translocation and DNA binding ability.

As shown in Figure 5A, treatment of $P$. vulgaris var. lilacina fractions $(50 \mu \mathrm{g} / \mathrm{mL})$ resulted in a significant decrease in NF- $\kappa$ B activation in LPS-stimulated RAW 264.7 cells as measured by using a firefly luciferase activity assay. Figure 5B shows the effect of $P$. vulgaris var. lilacina fractions on nuclear translocation of the p50 and p65 NF- $\mathrm{BB}$ subunits. The nuclear translocation of the p50 subunit was significantly reduced while the translocation of the p65 NF- $\kappa \mathrm{B}$ subunit was only slightly reduced by the hexane fraction of $P$. vulgaris var. lilacina. No other fractions affected the nuclear translocation of p50 or p65 NF-кB. 
Figure 5. Effect of Prunella vulgaris var. lilacina on NF- $\mathrm{BB}$ activation as measured by the luciferase assay (A), and on nuclear translocation of the p65 and p50 subunits (B) in LPS-stimulated RAW 264.7 cells. Cells were treated with fractions $(50 \mu \mathrm{g} / \mathrm{mL})$ and stimulated with LPS $(1 \mu \mathrm{g} / \mathrm{mL})$ for $12 \mathrm{~h} .{ }^{*} p<0.05$ significantly different from the LPS-stimulated PBS group.

(A)

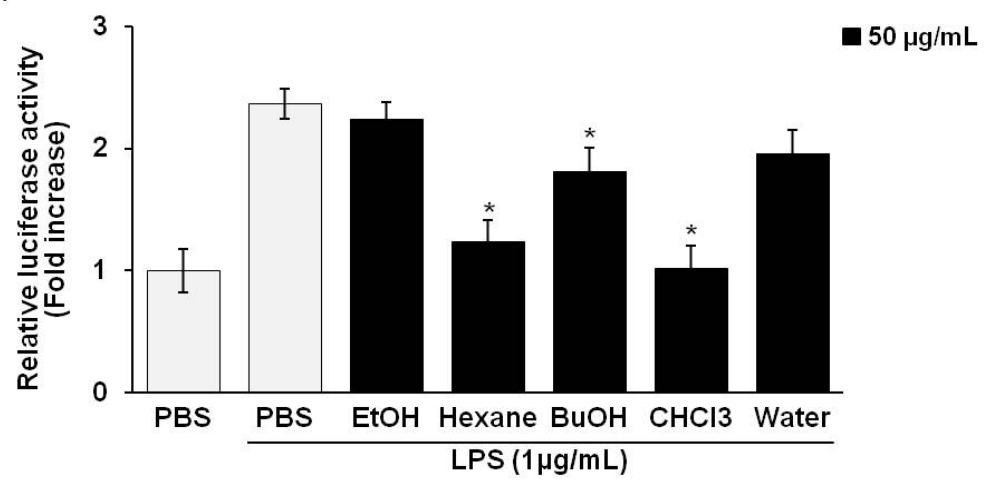

(B)

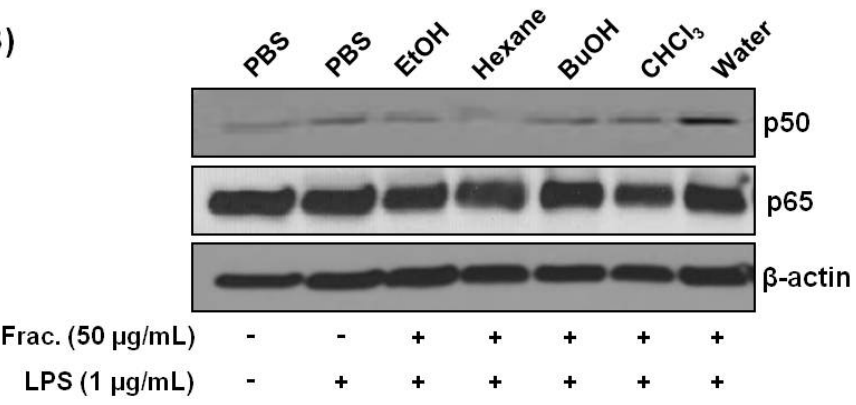

Many studies have demonstrated that $P$. vulgaris var. lilacina extracts regulate NF- $\mathrm{BB}$ activation. According to Jun et al. [13] reported that the ethanol extract of the flower of $P$. vulgaris var. lilacina inhibited NF- $\mathrm{NB}$ activity by $50 \%$, and Hwang et al. [14] reported that the water extract of $P$. vulgaris suppressed activation of the p65 NF- $\mathrm{BB}$ subunit. However, our results appear to differ from their results; we demonstrated that neither the ethanol nor the water extract of $P$. vulgaris var. lilacina affected the LPS-stimulated NF- $\mathrm{BB}$ activity. Instead, the hexane fraction of $P$. vulgaris var. lilacina inhibited both the p50 nuclear translocation and the NF- $\kappa \mathrm{B}$ activity in LPS-stimulated cells. These results clearly demonstrate that unlike the ethanol extract of P. vulgaris var. lilacina, the hexane fraction has other anti-inflammatory components.

\subsection{Identification of Components}

We isolated various compounds from the hexane fraction of $P$. vulgaris var. lilacina: the identified compounds are shown in Figure 6. The spectrum profile from the gas chromatography-mass spectrometry (GC-MS) analysis confirmed the presence of 12 major components: hexadecanoic acid, ethyl palmitate, phytol, ethyl linileate, $(Z, Z, Z)-9,12,15$-octadecatrien-1-ol, linoleic acid ethyl ester, $(Z, Z, Z)$-ethyl ester-9,12,15-octadecatrienoic acid, 3-oxo-8,beta, $H$-eudesma-1,4,7(11)-trien-8,12-olide, 3,7,11-trimethyl2,6,10-dodecatrien-1-ol, nerol, linalyl formate, and 3-ethylenetricyclo[3.3.1.1(3,7)]decane. 
Figure 6. Gas chromatogram and MS Spectra of hexane fractions from Prunella vulgaris var. lilacina. (A) Gas chromatogram of hexane fractions from Prunella vulgaris var. lilacina; (B) hexadecanoic acid; (C) ethyl palmitate; (D) phytol; (E) ethyl linileate; (F) $(Z, Z, Z)-9,12,15$-octadecatrien-1-ol; (G) linoleic acid ethyl ester; (H) (Z,Z,Z)-ethy lester-9,12,15-octadecatrienoic acid, (I) 3-oxo-8, beta, $H$-eudesma-1,4,7(11)-trien-8,12olide; (J) 3,7,11-trimethyl-2,6,10-dodecatrien-1-ol; (K) nerol; (L) linalyl formate, (M) 3-ethylenetricyclo[3.3.1.1(3,7)]decane.

(A)

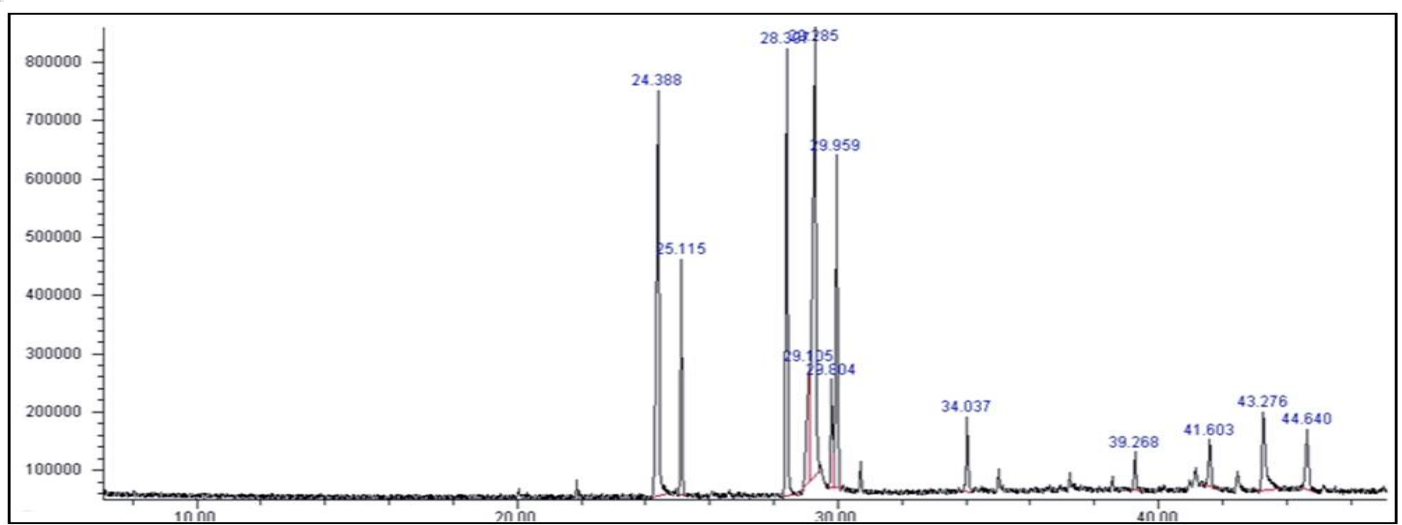

(B)

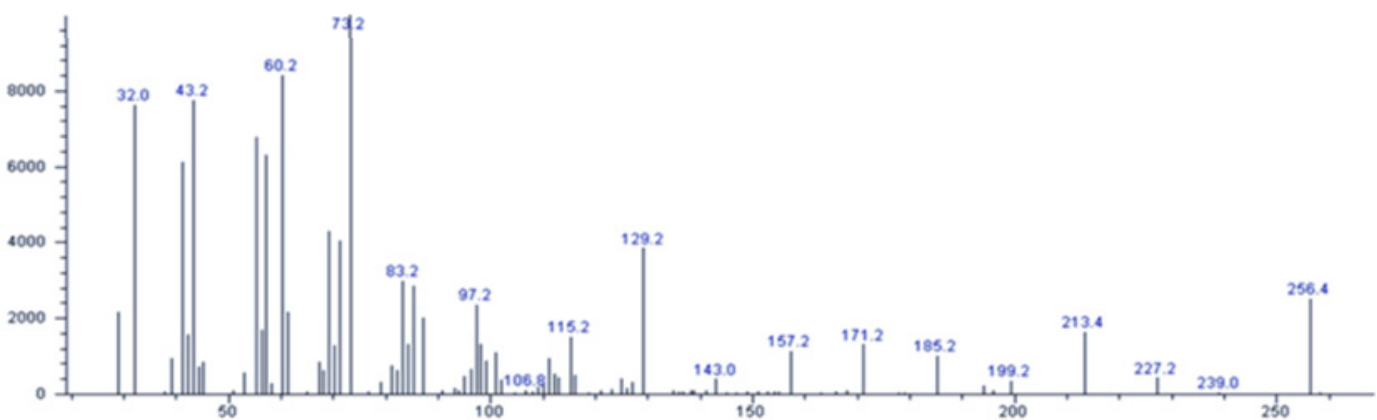

(C)

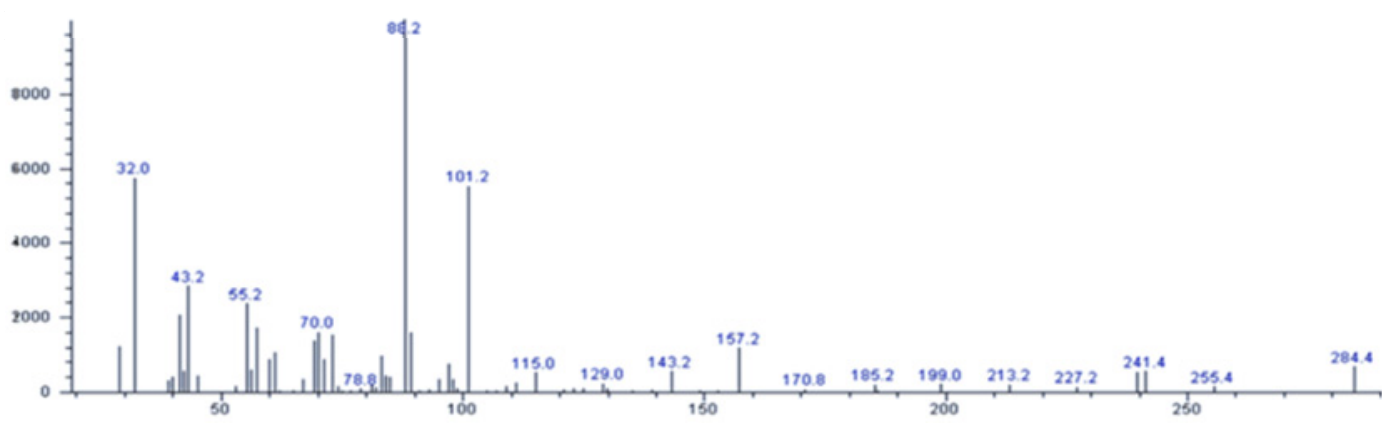

(D)

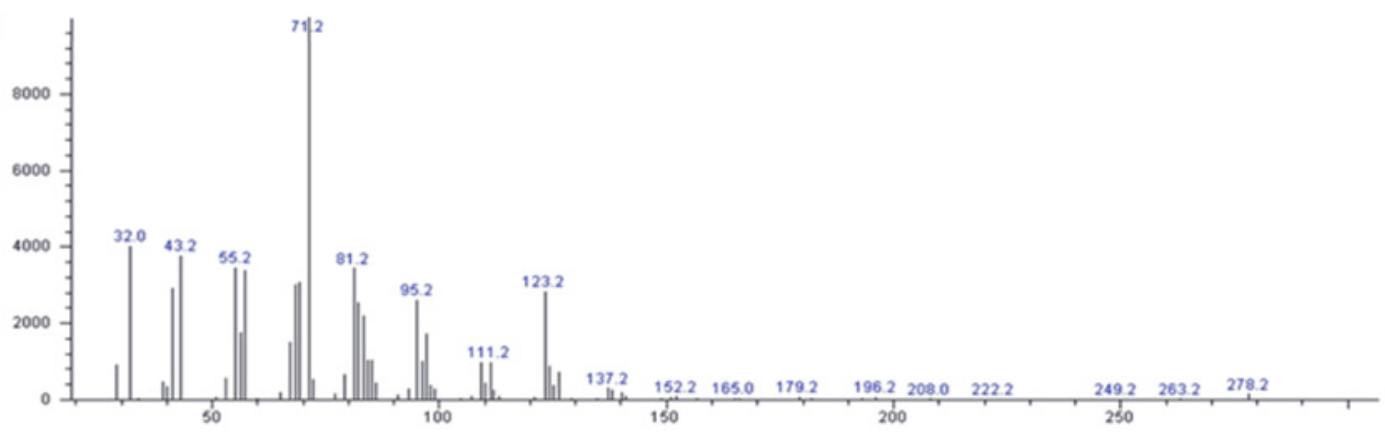


Figure 6. Cont.

(E)

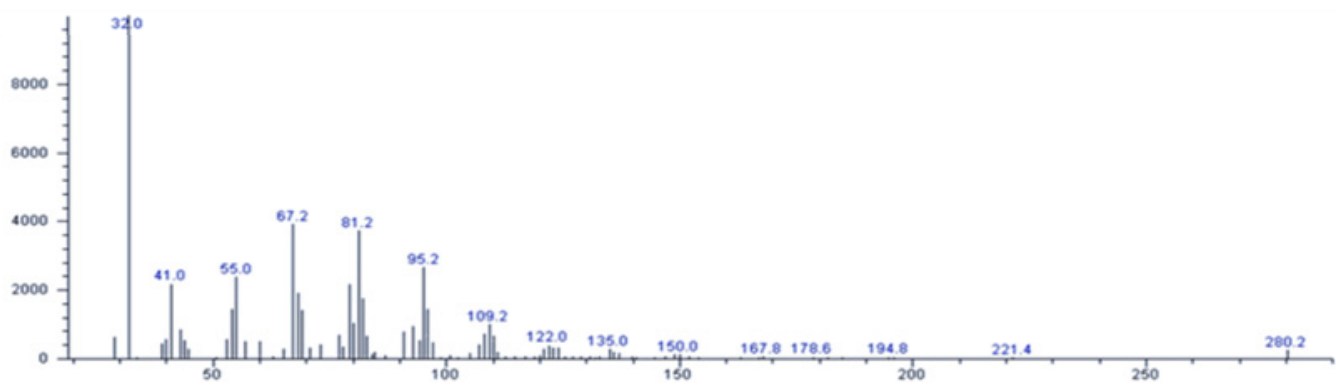

(F)

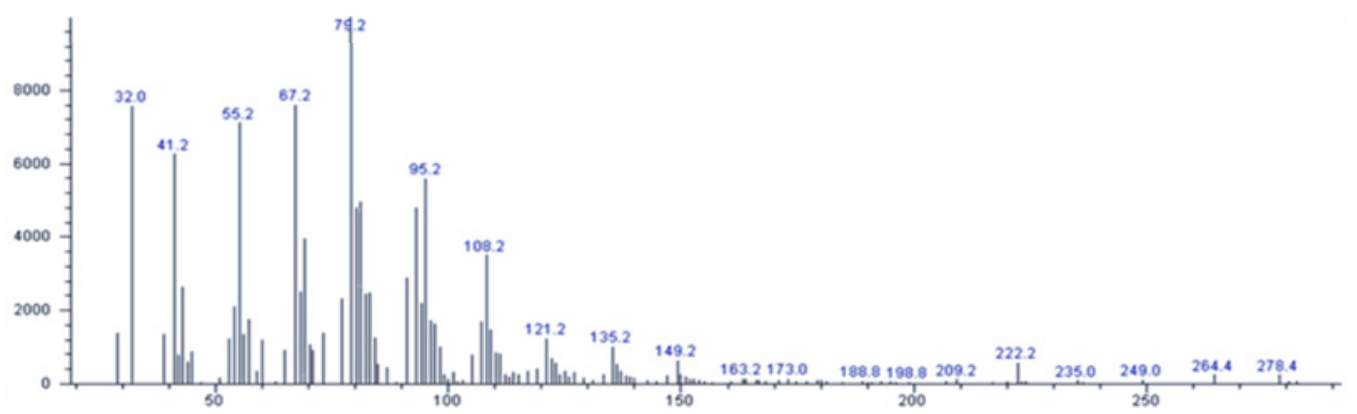

(G)

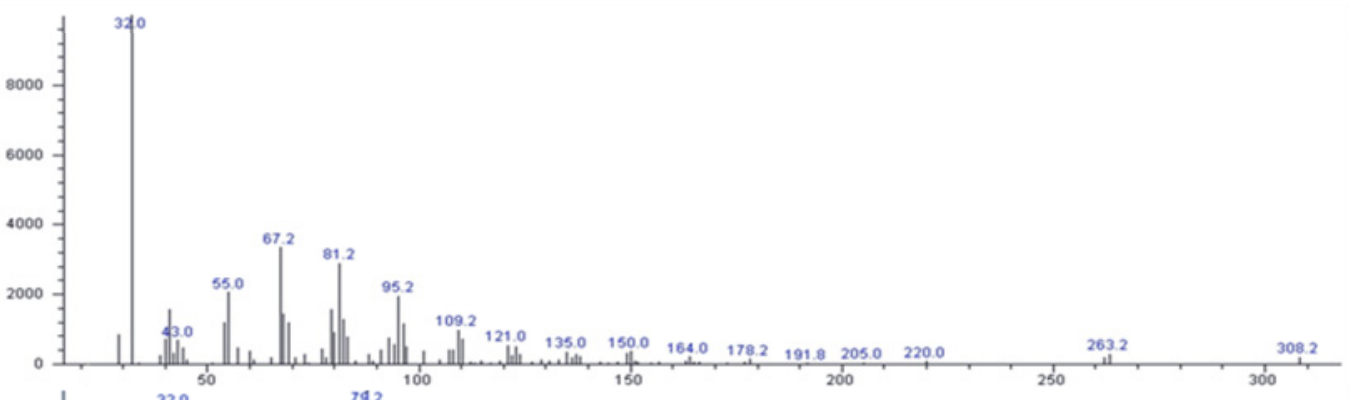

(H)

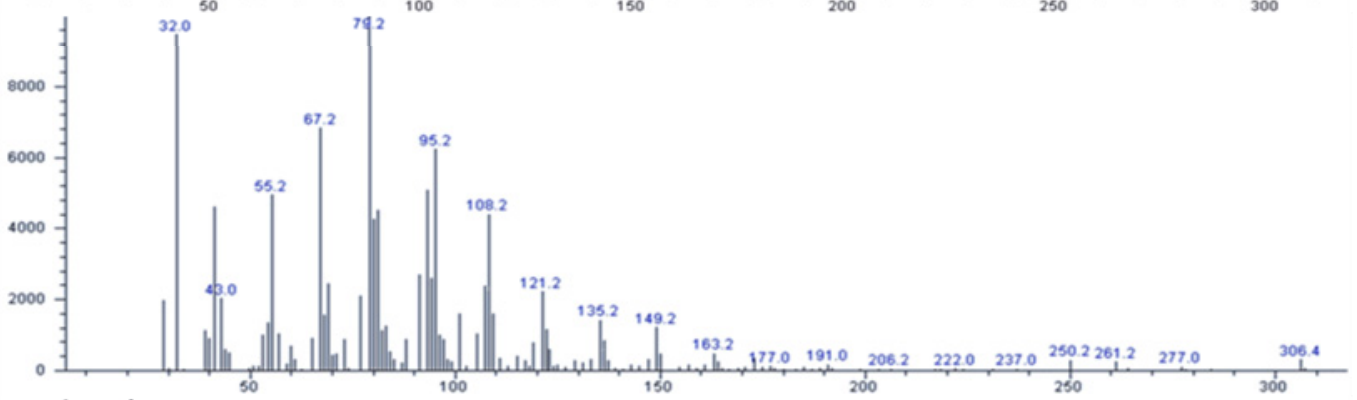

(I)

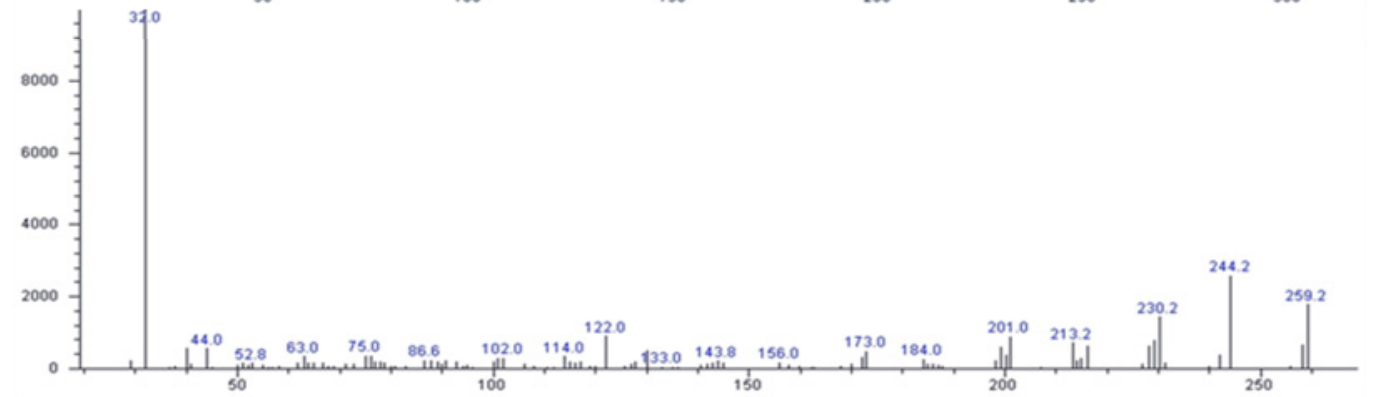

(J)

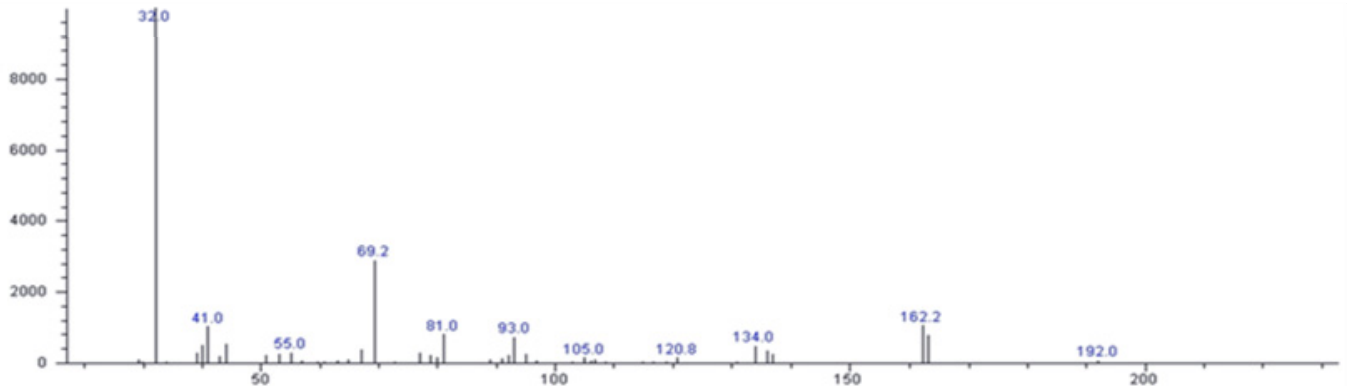


Figure 6. Cont.

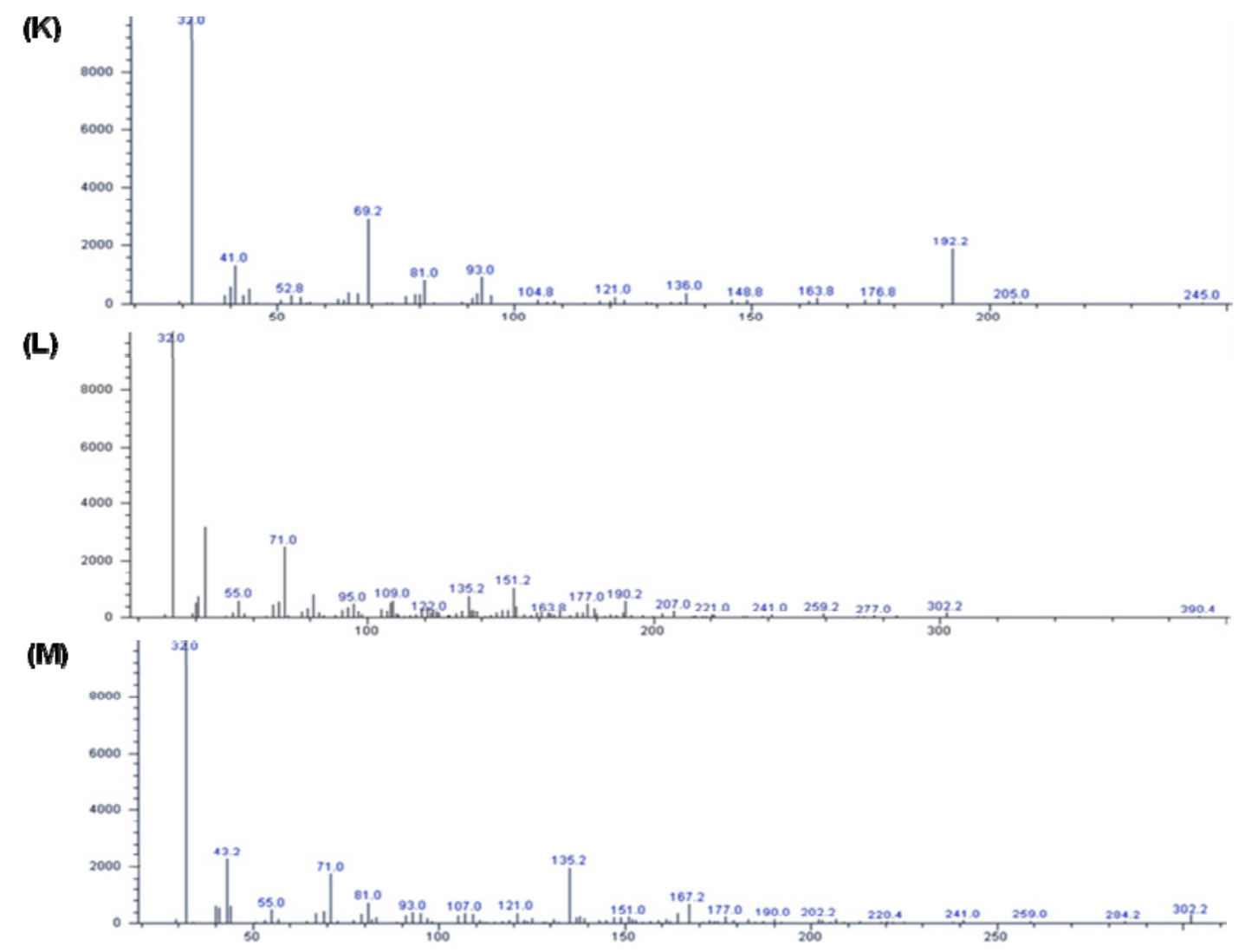

Several lipophilic compounds, including polyacetylenic acids, have been previously identified in the hexane fraction of P. vulgaris var. lilacina [27], and our research confirmed that this fraction indeed contained lipophilic compounds such as hexadecanoic acid, ethyl palmitate, and (Z,Z,Z)-ethyl ester-9,12,15-octadecatrienoic acid. It is well known that polyacetylenic acids have a therapeutic potential as antifungals and anti-oomycetes [27] while hexadecanoic acid, as an anti-inflammatory agent, has shown significant inhibitory activity against phospholipase A2 [28]. These reports are consistent with our results suggesting either that very potent unidentified anti-inflammatory compounds may be present in the hexane fraction of $P$. vulgaris var. lilacina or that hexadecanoic acid and other compounds may exert a synergistic effect on the inhibition of inflammatory mediator production in LPS-stimulated RAW 264.7 cells.

\section{Experimental Section}

\subsection{Reagents}

Dulbecco's Modified Eagle's Medium (DMEM), fetal bovine serum (FBS), and penicillin-streptomycin were obtained from Invitrogen (Carlsbad, CA, USA). LPS from Escherichia coli O55:B5 was purchased from Sigma-Aldrich (St. Louis, MO, USA). Antibodies against iNOS, COX-2, and $\beta$-actin were purchased from Cell Signaling Technology (Danvers, MA, USA). Monoclonal antibodies to p50 and p65 were purchased from Santa Cruz Biotechnology (Santa Cruz, Dallas, TX, USA). NF-кB-luciferase vector was purchased from Promega (Madison, WI, USA). All other chemicals were purchased from Sigma unless otherwise specified. 


\subsection{Sample Preparation and Extraction}

P. vulgaris var. lilacina was purchased from the Plant Extract Bank (Dae-jeon, Korea). The dried P. vulgaris var. lilacina was ground into fine powders in a blender and was extracted three times with $70 \%$ ethanol. Subsequently, $10 \mathrm{~g}$ of $70 \%$ ethanol extract powder were weighed and dissolved in $500 \mathrm{~mL}$ distilled water and extracted stepwise with $500 \mathrm{~mL}$ of the following solvents: hexane, chloroform, and butanol. Each fraction was filtered through number 6 filter paper (Advantec MFS, Inc., Tokyo, Japan). The filtrates were combined and evaporated under vacuum and then lyophilized with a Bondiro Lyophpride freeze dryer (Ilshine Lab Co. Ltd., Dongducheon, Korea) at $-70{ }^{\circ} \mathrm{C}$ under reduced pressure $(<20 \mathrm{~Pa})$.

\subsection{Cell Culture and Viability}

The RAW 264.7 macrophage cell line was purchased from the Korean Cell Line Bank (Seoul, Korea). RAW 264.7 cells were cultured in DMEM containing, 10\% FBS and 1\% penicillin/streptomycin at $37{ }^{\circ} \mathrm{C}$ in $5 \% \mathrm{CO}_{2}$. To investigate cell viability of $P$. vulgaris var. lilacina, cells $\left(1 \times 10^{4}\right.$ cells/well $)$ were added to duplicate 48 -well plates and incubated for $24 \mathrm{~h}$, then treated with various concentrations $(10,50$, and $100 \mu \mathrm{g} / \mathrm{mL})$ of fractions of $P$. vulgaris var. lilacina for $24 \mathrm{~h}$. Cell viability was measured with CellTiter Glo (Promega, Madison, WI, USA). The luminescent signal produced, which was proportional to the amount of ATP present in viable cells, was read on a Sirus luminometer (BertholdDetection System, Pforzheim, Germany). Cell viability is presented as the percentage of live cells in each well.

\subsection{Nitrite Measurement}

Nitrite was measured as an indicator of NO production after $48 \mathrm{~h}$ of treatment and LPS induction. The culture supernatant $(100 \mu \mathrm{L})$ was placed in a 96-well plate, and an equal amount of Griess reagent ( $2 \%$ sulphanilamide and $0.2 \% \mathrm{~N}$-1-(naphthyl) ethylenediamine dihydrochloride in $5 \% \mathrm{H}_{3} \mathrm{PO}_{4}$ ) was added. The plate was then incubated for $10 \mathrm{~min}$ and the absorbance measured at $540 \mathrm{~nm}$. The amount of NO was calculated using a sodium nitrite standard curve.

\subsection{Prostaglandin E2 Measurement}

After $12 \mathrm{~h}$ of treatment and LPS stimulation, the culture supernatant was collected. PGE2 was measured using a PGE2 ELISA kit following the manufacturer's instructions (Abcam, Cambridge, MA, USA). Briefly, the diluted cell supernatant $(100 \mu \mathrm{L})$ was placed in a 96-well goat anti-mouse IgG-coated plate and incubated for $2 \mathrm{~h}$. After incubation, the plate was washed using the provided washing buffer, and the color was developed by adding PNPP $(200 \mu \mathrm{L})$ substrate after $45 \mathrm{~min}$. The amount of PGE2 was calculated by using a PGE2 standard curve.

\subsection{Real-Time Reverse Transcription Polymerase Chain Reaction Analysis}

To determine the expression levels of iNOS, COX2, and TNF $\alpha$, real-time RT-PCR was performed using a real-time thermal cycler Qiagen rotorgene Q (Qiagen, Valencia, CA, USA) according to the 
manufacturer's instructions. The cells were treated with $P$. vulgaris var. lilacina fractions and cultured for $12 \mathrm{~h}$. Thereafter, cDNA was synthesized from the total RNA isolated from cells. The real-time PCR reaction was performed using $2 \times$ SYBR Green mix (Qiagen). All results were normalized to glyceraldehyde 3-phosphate dehydrogenase (GAPDH) expression. The following primer sequences were used for the real-time RT-PCR: GAPDH, 5'-GAG CCA AAA GGG TCA TCA TC-3' (forward), 5'-TAA GCA GTT GGT GGT GCA GG-3' (reverse); iNOS, 5'-AAT GGC AAC ATC AGG TCG GCC ATC ACT-3' (forward), 5'-GCT GTG TGT CAC AGA AGT CTC GAA CTC-3' (reverse); COX-2, 5'-GGA GAG ACT ATC AAG ATA GT-3' (forward), 5'-ATG GTC AGT AGA CTT TTA CA-3' (reverse); TNF $\alpha, 5$ '-AGC ACA GAA AGC ATG ATC CG-3' (forward), 5'-GTT TGC TAC GAC GTG GGC TA-3' (reverse).

\subsection{Immunoblotting}

Cells were lysed in RIPA buffer (150 mM Sodium Chloride, 1\% Triton X-100, 1\% sodium deoxycholate, $0.1 \%$ SDS, $50 \mathrm{mM}$ Tris-HCl, $\mathrm{pH} 7.5$, and $2 \mathrm{mM}$ EDTA) on ice for $30 \mathrm{~min}$. After centrifugation at $4{ }^{\circ} \mathrm{C}$ for $20 \mathrm{~min}(12,000 \times g)$, the supernatant was collected. Protein concentrations were determined by BCA assay (GenDEPOT, Barker, TX, USA). Equal amounts of cell extracts were separated by $12.5 \%$ SDS-PAGE and transferred to polyvinylidene difluoride (PVDF) membranes (Bio-Rad, Hercules, CA, USA). The membranes were blotted with antibody and detection was performed with an ECL system (Pierce, Rockford, IL, USA) according to the manufacturer's instructions.

\subsection{Cytokine Determinations}

The TNF $\alpha$ levels in the culture medium were determined by a Duo Set mouse TNF $\alpha$ ELISA kit according to the manufacturer's protocols ( $\mathrm{R} \& \mathrm{D}$ Systems, Minneapolis, MN, USA). The TNF $\alpha$ produced by LPS-treated cells was taken as $100 \%$.

\subsection{Transfection of RAW 264.7 Cells with $p N F-\kappa B$ Luciferase Vector}

RAW 264.7 cells were transiently transfected with a pNF-kB-luciferase vector (Promega) using Lipofectamine 2000 (Invitrogen, Carlsbad, CA, USA) following the manufacturer's protocol. Briefly, $5 \times 10^{4}$ cells were placed in a 24 -well plate and allowed to grow to $80 \%-90 \%$ confluency for $24 \mathrm{~h}$. The cells were then treated with DNA-Transfast reagent mixture $(50 \mu \mathrm{L})$ and incubated for $16 \mathrm{~h}$. The amount of DNA added was $0.25 \mu \mathrm{g} /$ well. After $16 \mathrm{~h}$ of incubation, each well was overlaid with $1 \mathrm{~mL}$ complete growth medium and the transfection was carried out for $48 \mathrm{~h}$.

\subsection{Measurement of NF- $\kappa B$ Luciferase Activity}

After transfection, cells were treated with fractions $(50 \mu \mathrm{g} / \mathrm{mL})$ and LPS $(1 \mu \mathrm{g} / \mathrm{mL})$ for $24 \mathrm{~h}$. Luciferase activity in the cells was measured using Dual-Luciferase Reporter Assay System (Promega) following the manufacturer's protocol. Briefly, growth medium was removed and the cells were washed with $1 \mathrm{~mL}$ ice-cold PBS. After complete removal of PBS, passive lysis buffer $(100 \mu \mathrm{L})$ was added and the plate incubated at room temperature for 15 min with shaking. After incubation, the luciferase activity was measured by adding cell lysate $(20 \mu \mathrm{L})$ to the luciferase assay reagent $(100 \mu \mathrm{L})$. 
Relative luciferase activity was determined by measuring the firefly luciferase activity and normalizing it to the Renilla luciferase activity.

\subsection{Gas Chromatography-Mass Spectrometry Analysis}

GC-MS analysis was carried out using an Agilent 6890 gas chromatograph equipped with a DB-5ms capillary column $(60 \mathrm{~m} \times 0.25 \mathrm{~mm}$; coating thickness $1.4 \mu \mathrm{m})$ and an Agilent $5975 \mathrm{MSD}$ detector (Loveland, CO, USA). Analytical conditions were as follows: injector and transfer line temperatures of $250{ }^{\circ} \mathrm{C}$; oven temperature was programmed from $50{ }^{\circ} \mathrm{C}$ to $150{ }^{\circ} \mathrm{C}$ at $10{ }^{\circ} \mathrm{C} / \mathrm{min}$, from $150{ }^{\circ} \mathrm{C}$ to $200{ }^{\circ} \mathrm{C}$ at $7{ }^{\circ} \mathrm{C} / \mathrm{min}$, and from $200{ }^{\circ} \mathrm{C}$ to $250{ }^{\circ} \mathrm{C}$ at $5^{\circ} \mathrm{C} / \mathrm{min}$; carrier gas helium at $1 \mathrm{~mL} / \mathrm{min}$; and split ratio 1:10. Identification of the constituents was based on comparison of the retention times with those of authentic samples. MS spectra of separated compounds were compared with one from Wiley 7 Nist 05 mass spectral database.

\subsection{Statistical Analysis}

Statistical analyses were performed with SPSS statistical software (version 12.0). The data represent means \pm SEM from 3 independent experiments except where indicated. Statistical analyses were performed by using the Student's $t$-test with $p<0.05$ considered significant.

\section{Conclusions}

In conclusion, our observations support the hypothesis that the hexane fraction of $P$. vulgaris var. lilacina exerts anti-inflammatory effects by inhibiting the expression of LPS-stimulated iNOS and COX-2 inflammation-associated genes via suppression of transcription factor NF- $\kappa \mathrm{B}$ activation. However, a limitation of our study is that our results were obtained by using cultured LPS-stimulated RAW 264.7 cells and, therefore, may differ from those results obtained in vivo. Thus, further studies will be required to investigate the anti-inflammatory effects of the hexane fraction of $P$. vulgaris var. lilacina in animal models of inflammation. In addition, the isolation and analysis of each anti-inflammatory compound from the hexane fraction of $P$. vulgaris var. lilacina is critical. Nevertheless, taken together, the results from our study suggest that the hexane fraction of $P$. vulgaris var. lilacina may be a potent anti-inflammatory therapeutic candidate.

\section{Acknowledgments}

This study was carried out with the support of the Research Program for Agricultural Science \& Technology Development (Project No. PJ008521), National Academy of Agricultural Science, Rural Development Administration, Suwon, Korea.

\section{Conflicts of Interest}

The authors declare no conflict of interest. 


\section{References}

1. Yuan, Q.; Zhang, X.; Liu, Z.; Song, S.; Xue, P.; Wang, J.; Ruan, J. Ethanol extract of Adiantum capillus-veneris L. suppresses the production of inflammatory mediators by inhibiting NF-кB activation. J. Ethnopharmacol. 2013, 147, 603-611.

2. De Heredia, F.P.; Gomez-Martinez, S.; Marcos, A. Obesity, inflammation and the immune system. Proc. Nutr. Soc. 2012, 71, 332-338.

3. Alderton, W.K.; Cooper, C.E.; Knowles, R.G. Nitric oxide synthases: Structure, function and inhibition. Biochem. J. 2001, 357, 593-615.

4. Bredt, D.S. Endogenous nitric oxide synthesis: Biological functions and pathophysiology. Free Radic. Res. 1999, 31, 577-596.

5. Kleinert, H.; Pautz, A.; Linker, K.; Schwarz, P.M. Regulation of the expression of inducible nitric oxide synthase. Eur. J. Pharmacol. 2004, 500, 255-266.

6. Tak, P.P.; Firestein, G.S. NF-kappaB: A key role in inflammatory diseases. J. Clin. Investig. 2001, 107, 7-11.

7. Karin, M.; Yamamoto, Y.; Wang, Q.M. The IKK NF-kappa B system: A treasure trove for drug development. Nat. Rev. Drug Discov. 2004, 3, 17-26.

8. Haddad, P.S.; Azar, G.A.; Groom, S.; Boivin, M. Natural health products, modulation of immune function and prevention of chronic disease. Evid. Based Complement. Altern. Med. 2005, 2, 513-520.

9. Garcia-Lafuente, A.; Guillamon, E.; Villares, A.; Rostagno, M.A.; Martinez, J.A. Flavonoids as anti-inflammatory agents: Implications in cancer and cardiovascular disease. Inflamm. Res. 2009, 58, 537-552.

10. Ryu, S.Y.; Oak, M.H.; Yoon, S.K.; Cho, D.I.; Yoo, G.S.; Kim, T.S.; Kim, K.M. Antiallergic and anti-inflammatory triterpenes from the herb of Prunella vulgaris. Planta Med. 2000, 66, 358-360.

11. Psotová, J.; Kolár, M.; Sousek, J.; Svagera, Z.; Vicar, J.; Ulrichová, J. Biological activities of Prunella vulgaris extract. Phytother. Res. 2003, 17, 1082-1087.

12. Lamaison, J.L.; Petitjean-Freytet, C.; Carnat, A. Medicinal Lamiaceae with antioxidant properties, a potential source of rosmarinic acid. Pharm. Acta Helv. 1991, 66, 185-188.

13. Jun, M.S.; Kim, H.S.; Kim, Y.M.; Kim, H.J.; Park, E.J.; Lee, J.H.; Lee, K.R.; Kim, Y.S.; Chang, K.C. Ethanol extract of Prunella vulgaris var. lilacina inhibits HMGB1 release by induction of heme oxygenase-1 in LPS-activated RAW 264.7 cells and CLP-induced septic mice. Phytother. Res. 2012, 26, 605-612.

14. Hwang, S.M.; Lee, Y.J.; Yoon, J.J.; Lee, S.M.; Kim, J.S.; Kang, D.G.; Lee, H.S. Prunella vulgaris suppresses HG-induced vascular inflammation via Nrf2/HO-1/eNOS activation. Int. J. Mol. Sci. 2012, 13, 1258-1268.

15. Kim, S.-Y.; Kim, S.-H.; Shin, H.-Y.; Lim, J.-P.; Chae, B.-S.; Park, J.-S.; Hong, S.-G.; Kim, M.-S.; Jo, D.-G.; Park, W.-H.; et al. Effects of Prunella vulgaris on mast cell-mediated allergic reaction and inflammatory cytokine production. Exp. Biol. Med. 2007, 232, 921-926.

16. Huang, N.; Hauck, C.; Yum, M.Y.; Rizshsky, L.; Widrlechner, M.P.; McCoy, J.A.; Murphy, P.A.; Dixon, P.M.; Nikolau, B.J.; Birt, D.F. Rosmarinic acid in Prunella vulgaris ethanol extract inhibits lipopolysaccharide-induced prostaglandin E2 and nitric oxide in RAW 264.7 mouse macrophages. J. Agric. Food Chem. 2009, 57, 10579-10589. 
17. Hostanska, K.; Nisslein, T.; Freudenstein, J.; Reichling, J.; Saller, R. Inhibitory effect of an isopropanolic extract of black cohosh on the invasiveness of MDA-mB 231 human breast cancer cells. In Vivo 2007, 21, 349-355.

18. Zielinska-Przyjemska, M.; Olejnik, A.; Dobrowolska-Zachwieja, A.; Grajek, W. Effects of Aronia melanocarpa polyphenols on oxidative metabolism and apoptosis of neutrophils from obese and non-obese individuals. ACTA Sci. Pol. Technol. Aliment. 2007, 6, 75-87.

19. Chung, J.W.; Choi, R.J.; Seo, E.K.; Nam, J.W.; Dong, M.S.; Shin, E.M.; Guo, L.Y.; Kim, Y.S. Anti-inflammatory effects of $(Z)$-ligustilide through suppression of mitogen-activated protein kinases and nuclear factor-кB activation pathways. Arch. Pharm. Res. 2012, 35, 723-732.

20. Korhonen, R.; Lahti, A.; Kankaanranta, H.; Moilanen, E. Nitric oxide production and signaling in inflammation. Curr. Drug Targets Inflamm. Allergy 2005, 4, 471-479.

21. Tsatsanis, C.; Androulidaki, A.; Venihaki, M.; Margioris, A.N. Signalling networks regulating cyclooxygenase-2. Int. J. Biochem. Cell Biol. 2006, 38, 1654-1661.

22. Sugita, T. Targeting therapy for inflammatory diseases by anti-TNFalpha biologics. Yakugaku Zasshi 2009, 129, 19-24.

23. Shapira, L.; Soskolne, W.A.; Houri, Y.; Barak, V.; Halabi, A.; Stabholz, A. Protection against endotoxic shock and lipopolysaccharide-induced local inflammation by tetracycline: Correlation with inhibition of cytokine secretion. Infect. Immun. 1996, 64, 825-828.

24. Medzhitov, R.; Horng, T. Transcriptional control of the inflammatory response. Nat. Rev. Immunol. 2009, 9, 692-703.

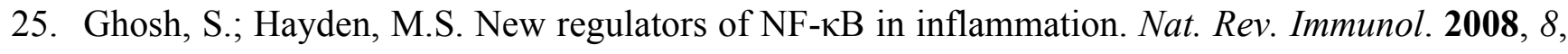
837-848.

26. Akira, S.; Takeda, K. Toll-like receptor signalling. Nat. Rev. Immunol. 2004, 4, 499-511.

27. Yoon, M.Y.; Choi, G.J.; Choi, Y.H.; Jang, K.S.; Park, M.S.; Cha, B.; Kim, J.C. Effect of polyacetylenic acids from Prunella vulgaris on various plant pathogens. Lett. Appl. Microbiol. 2010, 51, 511-517.

28. Aparna, V.; Dileep, K.V.; Mandal, P.K.; Karthe, P.; Sadasivan, C.; Haridas, M. Anti-inflammatory property of n-hexadecanoic acid: Structural evidence and kinetic assessment. Chem. Biol. Drug Des. 2012, 80, 434-439.

(C) 2013 by the authors; licensee MDPI, Basel, Switzerland. This article is an open access article distributed under the terms and conditions of the Creative Commons Attribution license (http://creativecommons.org/licenses/by/3.0/). 